Meteorol. Atmos. Phys. 41, 247-254 (1989)

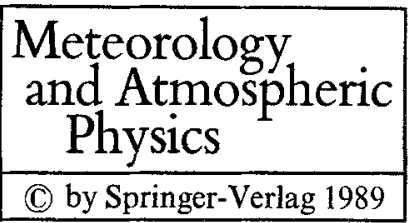

551.576 .1

DLR ${ }^{1}$-Institute for Atmospheric Physics, Oberpfaffenhofen, Federal Republic of Germany

\title{
Cloudphysical Parameters in Dependence on Height Above Cloud Base in Different Clouds
}

\author{
H.-E. Hoffmann and R. Roth
}

With 5 Figures

Received February 9, 1989

Revised August 7, 1989

\section{Summary}

On flights with the DLR icing research aircraft the dependence of aircraft icing on cloudphysical parameters was determined; both for aircraft-referred icing and for normalized icing, as well as for various clouds and locations in clouds. This is done with an improvement of icing predicitons in mind. The species of the cloud and the distance from cloud base are called here "cloud parameters"; while under "cloudphysical parameters" are understood liquid water content, temperature, particle size distribution and particle phase. Results from four icing flights are discussed, selected from a total of forty vertical soundings. - The results are arranged in four classes: Stratus/cumulus mixed, stratus; with and without precipitation at the ground.

1. Stratus/cumulus with either simultaneous or earlier $(3 \mathrm{~h})$ precipitation at ground: Maxima of liquid water content ( $L W C: 0.75$ and $0.55 \mathrm{~g} / \mathrm{m}^{3}$, resp.) and maxima of the median volume diameter (MVD: 183 and $123 \mu \mathrm{m}$, resp.) both located in lower half of clouds.

2. Stratus/cumulus without precipitation: Maximum of $L W C\left(0.45 \mathrm{~g} / \mathrm{m}^{3}\right)$ in upper third of cloud, but $M V D$ increasing from base to top of cloud ( 7 to $20 \mu \mathrm{m}$ ).

3. Stratus with precipitation: No results.

4. Stratus without precipitation: Both $L W C$ and $M V D$ increase from base to top of cloud; maxima directly beneath cloud top: $L W C 0.50 \mathrm{~g} / \mathrm{m}^{3} ; M V D 17 \mu \mathrm{m}$.

${ }^{1}$ DLR, formerly DFVLR = Deutsche Forschungsanstalt für Luft- und Raumfahrt (German Aerospace Research Establishment).

\section{Introduction}

About four years ago, the Institute for Atmospheric Physics of the DLR began to work on research project "Icing of aircraft", One of the objects of this research is defined by Hoffmann and Demmel (1984) as Determination of Flight Restrictions of Aircraft Caused by Icing in Dependence on Meteorological Parameters.

Meteorological parameters here are: Cloudphysical, synoptic and cloud parameters. First results, concerning the dependence of the normalized ice thickness, and by this also of the normalized icing-degree, on the cloudphysical parameters liquid water content, temperature, particle size distribution and particle phase, were published in the report mentioned above and in Hoffmann et al. (1986). Normalized ice thickness is the ice thickness in flow direction on metal cylinders with diameters of $12.5 ; 25.0$ and $50.0 \mathrm{~mm}$ on a flight path in clouds of 10 nautical miles at a flight velocity of about $125 \mathrm{kt}$. Figure 1 was taken from Hoffmann (1988) and shows the dependence of the normalized icing-degree and the normalized icing thickness on the total water content. Total water content here is the water content formed by liquid and also by solid particles. The regression 


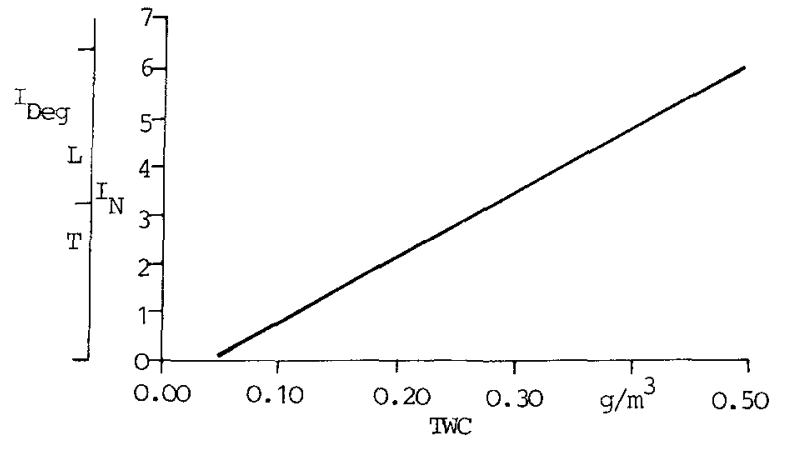

Fig. 1. The normalized icing-degree $I_{D e g}$ and the normalized icing thickness $I_{N}$ on a cylinder with a diameter of $12.5 \mathrm{~mm}$ in dependence on total water content $T W C$. Temperature: 0 to $-16^{\circ} \mathrm{C}$, particle size distribution $(M V D)$ : 13 to $340 \mu \mathrm{m}$, phase of particles: Liquid or mixed

T: Normalized icing-degree Trace; L: Normalized icing-degree Light

line of Fig. 1 represents 53 single results. These were obtained on 53 flight sections for determining the normalized icing-degree during the icing flights of the winter $1984 / 85$. The regression line is valid for temperatures between 0 and $-16^{\circ} \mathrm{C}$ and $M V D$-values between 13 and $300 \mu \mathrm{m}$. From Fig. 1 results: Under the test conditions of Fig. 1 the normalized icing-degree is linearily growing with increasing total water content. The normalized icing-degree "trace" is attained at total water content values of up to $0.30 \mathrm{~g} / \mathrm{m}^{3}$ and the normalized icing-degree "light" at total water content values between 0.30 and $0.50 \mathrm{~g} / \mathrm{m}^{3}$. At total water content values greater than $0.50 \mathrm{~g} / \mathrm{m}^{3}$ you have to expect the normalized icing-degree to be moderate up to severe.

Such a simple statement as for the normalized icing-degree cannot be made for the aircraft-referred icing-degrees, according to the test results obtained up to now. The causes for this are that their definitions are very unprecise, see Air Weather Service (1980) and Hoffmann (1988), but also the difficulties to obtain them in flight experiments. The values of Table 1, too, which also was taken from Hoffmann (1988), are based on the results of the icing flight sections of the winter $1984 / 85$. The values for the cloudphysical parameters temperature, total water content and median volume diameter of the left half of Table 1 are mean values and represent the cloudphysical situation for the aircraft-referred icing-degree trace to light. The mean values of the right half represent
Table 1. The Icing-Relevant Cloudphysical Parameters Temperature T, Total Water Content TWC, and Median Volume Diameter MVD for Do 28 Aircraft Referred Icing Degrees "Trace" to "Light" and "Moderate" to "Severe"

\begin{tabular}{ll}
\hline$T\left[{ }^{\circ} \mathrm{C}\right]:$ & $T\left[{ }^{\circ} \mathrm{C}\right]:$ \\
$-7.8(-4.2 ;-10.8)$ & $-3.7(-2.0 ;-7.9)$ \\
$T W C\left[\mathrm{~g} / \mathrm{m}^{3}\right]:$ & $T W C\left[\mathrm{~g} / \mathrm{m}^{3}\right]:$ \\
$0.19(0.04 ; 0.44)$ & $0.12(0.05 ; 0.31)$ \\
$M V D[\mu \mathrm{m}]:$ & $M V D[\mu \mathrm{m}]:$ \\
$14.5(11.0 ; 18.5)$ & $26.5(15.0 ; 36.5)$ \\
\hline
\end{tabular}

Do 28 aircraft referred icing degree trace to light

Do 28 aircraft referred icing degree moderate to severe

the cloudpyhsical situation for the aircraft-referred icing-degree moderate to severe. Reference aircraft here is the DLR icing research aircraft of type Do 28 . The mean values of the left part were obtained from 37 single values and those of the right part from 17 single values. The values in parantheses are the minimum, respectively maximum values. When the temperature was relative high - mean value $-3.7^{\circ} \mathrm{C}$ - and when there were big particles in the particle spectrum - mean value for the median volume diameter $26.5 \mu \mathrm{m}$ - the aircraft-referred icing-degree was moderate to severe. Significant differences of the value for the total water content cannot be seen in both the icingdegree ranges of Table 1. The aircraft-referred icing-degree moderate to severe was caused by the ice which was built up on the wing underside. When the liquid cloud particles are big, and the temperature is relatively high, only a part of the water impinging upon the front edge of the wing is freezing instantly. The other part is running on the underside of the wing where it is freezing, see also Sand et al. (1984).

Here the results of four icing flights are reported at which three different stratus/cumulus clouds and one stratus cloud could be traversed from their tops to their bases or vice versa. At the same time, the cloudphysical parameters liquid water content, particle size distribution and temperature were measured. These 4 vertical soundings are a selection from all the 40 soundings which could be conducted and evaluated so far and are representative for the classes in which the results, hitherto existing, are summarized: Stratus/cumulus cloudiness (mixed cloudiness) and stratus cloudiness, without and with precipitation on the ground, see 
Hoffmann et al. (1988). All results, existing and of the future, shall serve for an extension of a climatology of icing relevant cloudphysical parameters, see Roach et al. (1984).

\section{Test Procedure, Used Instruments, and Preparation of Measured Values}

For conducting icing flights from DLR a twopropeller aircraft of type Do 28 has been equipped as an icing research aircraft. From this, all icing relevant atmospheric parameters and the icing can be measured. The icing is measured on three metal cylinders and on the front edge and on the underside of one of the wings, see Hoffmann and Demmel (1986).

The values for the liquid water content $(L W C)$, given in the following, were obtaind from a Johnson-Williams hot wire instrument (J.-W.). A Forward Scattering Spectrometer Probe (FSSP) and an Optical Array Probe (OAP), both manufactured by Particle Measuring Systems (PMS) at Boulder, were used for measuring the size and the number pro unit volume of the cloud particles. FSSP is measuring the particle size up to diameters of $47 \mu \mathrm{m}$ by forward scattering of light and OAP up to diameters of $600 \mu \mathrm{m}$ by 1 -dimensional imaging. For the determination of the value for the median volume diameter $(M V D)$, the $L W C$ values, derived from $P M S$ measurements were used. To eliminate additional problems, concerning the size determination of cloud particles in mixed phased particle populations measurements were used only when the particles were all liquid. The discrimination between only liquid, mixed phased and only solid particles was done by visual observation by the pilots and measuring engineers and by means of the character of the signals of a Csiro-King hot wire instrument and of a backscatter probe. The signals of both the instruments demonstrate sig-
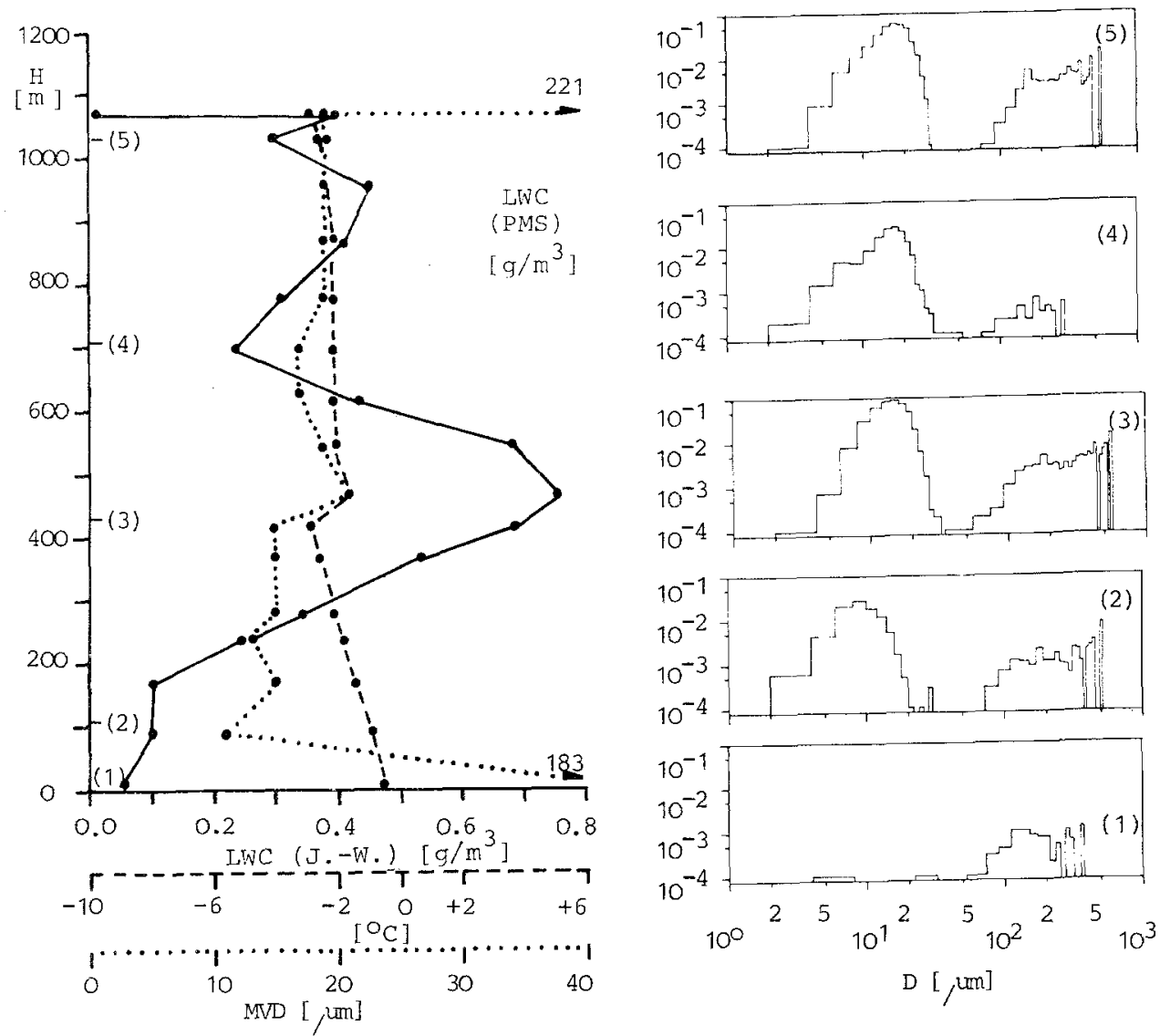

Fig. 2. Liquid water content, measured by hot wire instrument Johnson-Williams, $L W C$ (J.-W.), temperature $T$, and median volume diameter $M V D$ as a funciton of height above cloudbase $H$ (left-hand) and liquid water content, measured by Particle Measuring System's instruments, $L W C$ (PMS) as a function of particle diameter $D$ for 5 different points (right-hand) in $8 / 8$ stratus/cumulus cloudiness with precipitation (little to moderate show) 
nificant signal peaks when solid particles are present, see Hoffmann and Demmel (1986) and Hoffmann (1986). The Csiro-King hot-wire instrument serves for the determination of the liquid water content, too, whereas by the backscatter probe information on the horizontal standard visibility and on the type of the particle size distribution are derived. The cloud temperature was determined by a Rosemount resistance thermometer, the housing of which is de-iced by electric heating.

All the measurements were conducted on flights over southern Germany in winter month between the northern border of the Alps and a distance of about $60 \mathrm{~km}$ to the north. The points of the plottings of the left parts of the figures in the next section are mean values for flight parts of $20 \mathrm{sec}$ duration.

\section{Results}

The following 4 figures contain on the left the plots of the values for liquid water content $L W C$ $\left(\mathrm{g} / \mathrm{m}^{3}\right)$, static air temperature $T\left({ }^{\circ} \mathrm{C}\right)$, and median volume diameter $M V D(\mu \mathrm{m})$ for different heights above cloudbase. On the right in each figure are depicted the $L W C$ values in dependence on particle diameter $D$ for a different number of lefthand points. In Table 2 the $L W C, T$, and $M V D$ values for these special points are listed but beyond these also the values for the mean particle diameter $D$ and the concentration number (that is the number of particles pro $\mathrm{cm}^{3}$ ). Table 3 gives some additional information concerning the cloud situation. The data of both the tables may be of interest also for an icing climatology.
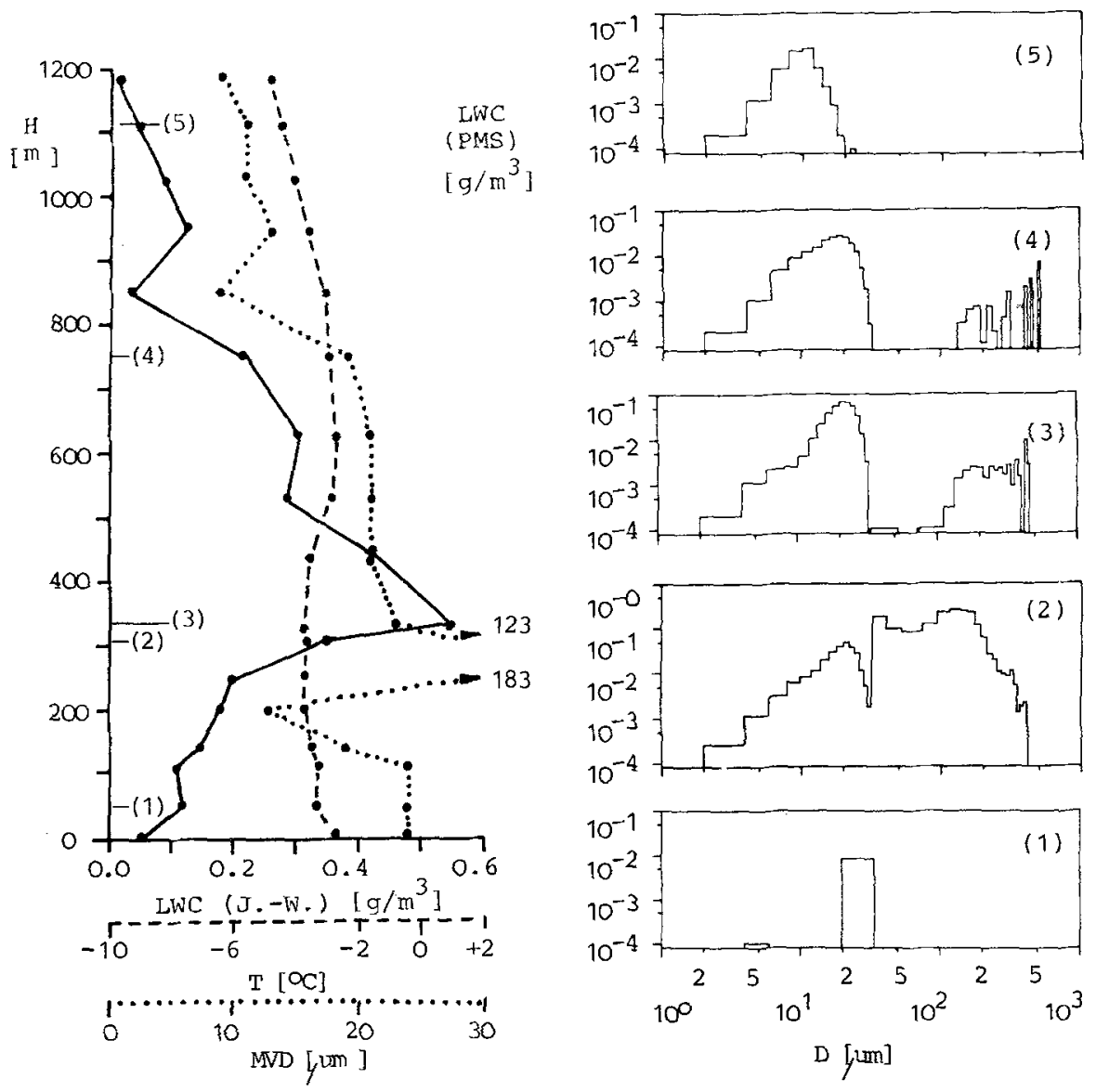

Fig. 3. Liquid water content, measured by hot wire instrument Johnson-Williams, $L W C$ (J.-W.), temperature $T$, and median volume diameter $M V D$ as a function of height above cloudbase $H$ (left-hand) and hquid water content, measured by Particle Measuring System's instruments, LWC (PMS) as a function of particle diameter $D$ for 5 different points (right-hand) in $8 / 8$ stratus/cumulus cloudiness without precipitation (but about $3 \mathrm{~h}$ after precipitation; little to moderate snow) 

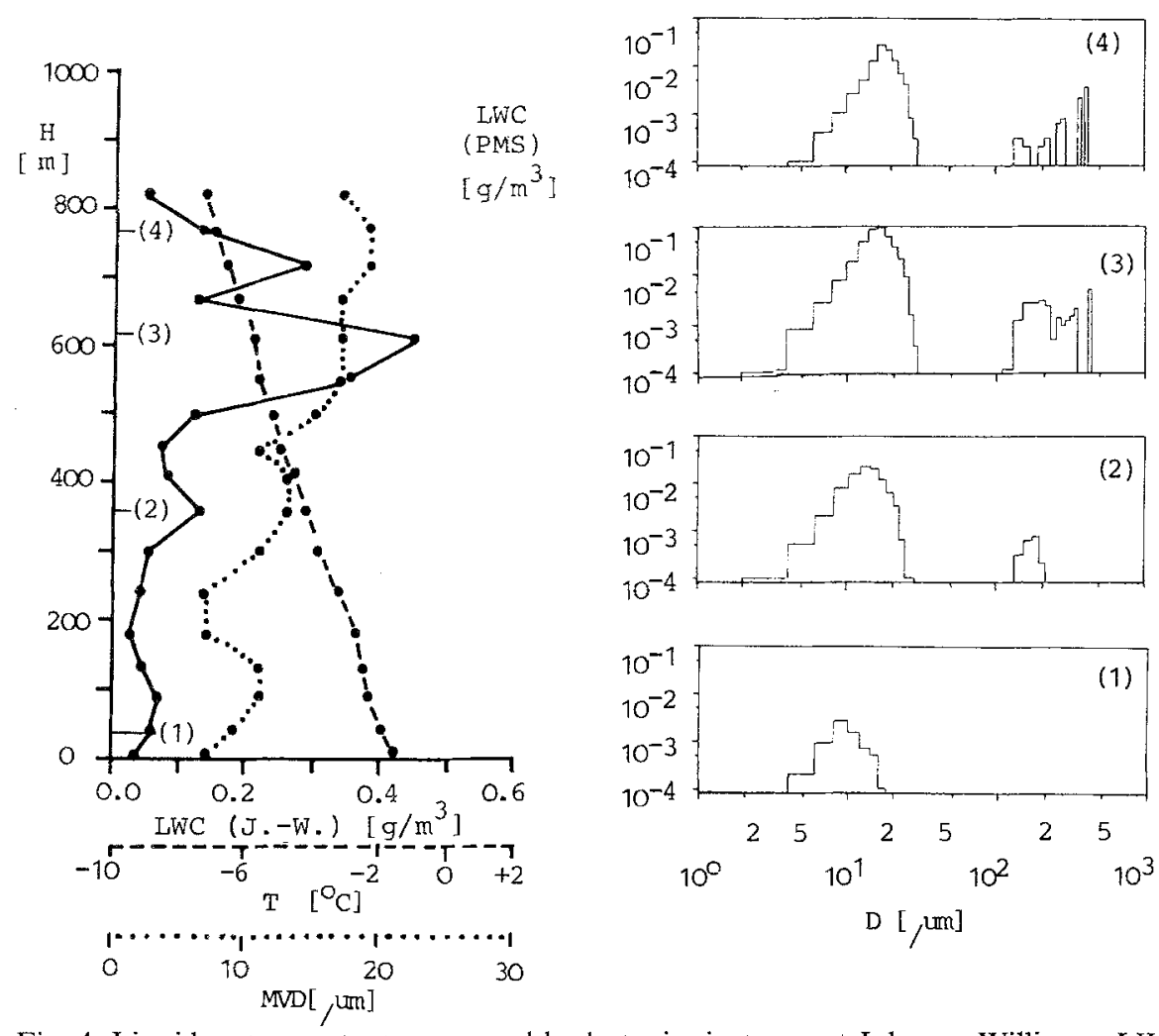

Fig. 4. Liquid water content, measured by hot wire instrument Johnson-Williams, $L W C$ (J.-W.), temperature $T$, and median volume diameter $M V D$ as a function of height above cloudbase $H$ (left-hand) and liquid water content, measured by Particle Measuring System's instruments, $L W C$ (PMS) as a function of particle diameter $D$ for 4 different points (right-hand) in $5 / 8$ to $6 / 8$ stratus/cumulus cloudiness without precipitation
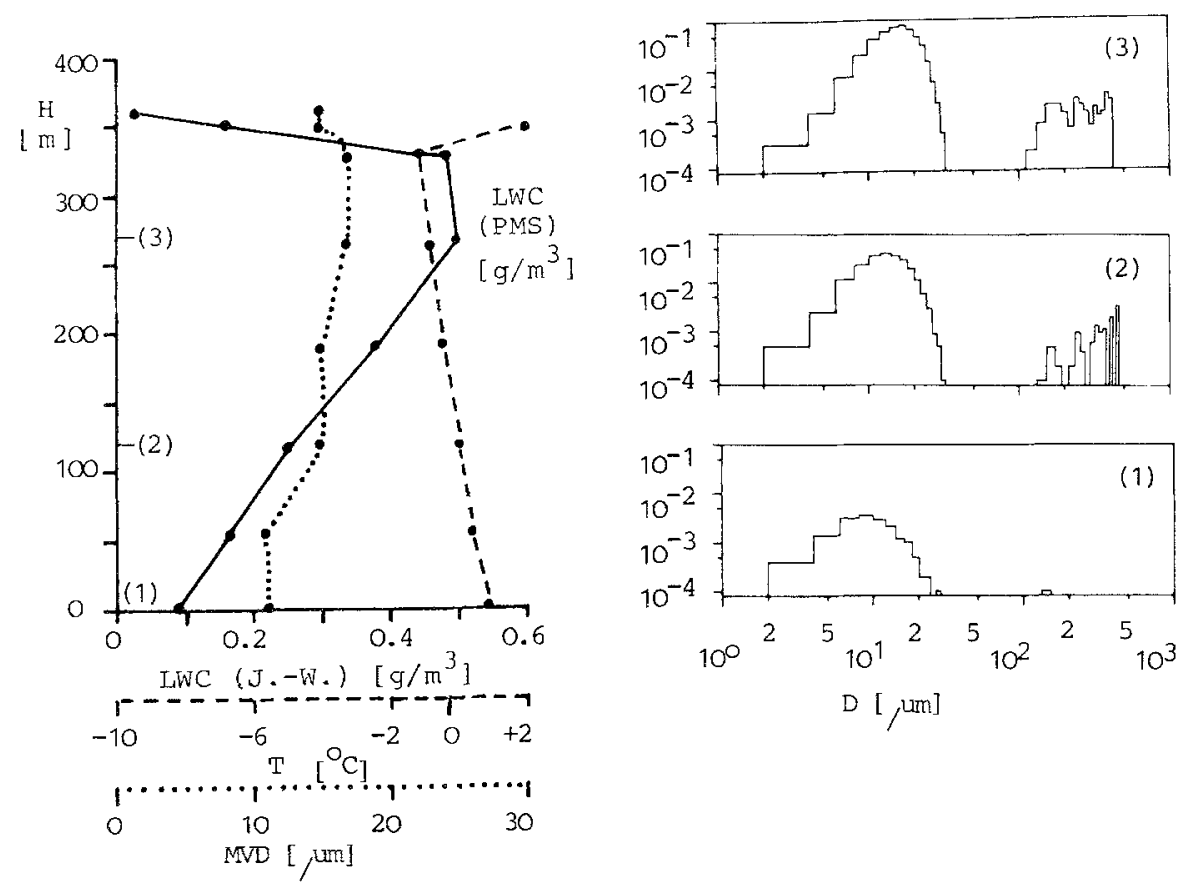

$D[$, um $]$

Fig. 5. Liquid water content, measured by hot wire instrument Johnson-Williams, $L W C$ (J.-W.), temperature $T$, and median volume diameter $M V D$ as a function of height above cloudbase $H$ (left-hand) and liquid water content, measured by Particle Measuring System's instruments, LWSC (PMS) as a funciton of particle diameter $D$ for 3 different points (right-hand) in $8 /$ 8 stratus cloudiness without precipitation 
Table 2. The Values for Height Above Cloud Base H, Liquid Water Content LWC (J.-W.), Temperature T, Median Volume Diameter MVD, Mean Diameter D, Particle Concentration N, and Airmass for the Points Specially Marked in the Figs. 2 to 5

\begin{tabular}{|c|c|c|c|c|c|c|c|c|}
\hline $\begin{array}{l}\text { Fig. } \\
\text { No. }\end{array}$ & $\begin{array}{l}\text { Point } \\
\text { No. }\end{array}$ & $\begin{array}{l}H \\
{[\mathrm{~m}]}\end{array}$ & $\begin{array}{l}L W C \\
\mathrm{~J} .-\mathrm{W} . \\
{\left[\mathrm{g} / \mathrm{m}^{3}\right]}\end{array}$ & $\begin{array}{l}T \\
{\left[{ }^{\circ} \mathrm{C}\right]}\end{array}$ & $\begin{array}{l}M V D \\
{[\mu \mathrm{m}]}\end{array}$ & $\begin{array}{l}\bar{D} \\
{[\mu \mathrm{m}]}\end{array}$ & $\begin{array}{l}N \\
{\left[\frac{\text { Number }}{\mathrm{cm}^{3}}\right]}\end{array}$ & Airmass \\
\hline 2 & $\begin{array}{l}5 \\
4 \\
3 \\
2 \\
1\end{array}$ & $\begin{array}{r}1030 \\
700 \\
420 \\
90 \\
0\end{array}$ & $\begin{array}{l}0.29 \\
0.23 \\
0.69 \\
0.10 \\
0.05\end{array}$ & $\begin{array}{l}-2.2 \\
-2.0 \\
-1.8 \\
-0.8 \\
-0.5\end{array}$ & $\begin{array}{r}19 \\
17 \\
15 \\
11 \\
183\end{array}$ & $\begin{array}{r}13 \\
10 \\
12 \\
7 \\
14\end{array}$ & $\begin{array}{r}226 \\
138 \\
416 \\
344 \\
4\end{array}$ & $m S_{p}$ \\
\hline 3 & $\begin{array}{l}5 \\
4 \\
3 \\
2 \\
1\end{array}$ & $\begin{array}{r}1110 \\
750 \\
330 \\
310 \\
50\end{array}$ & $\begin{array}{l}0.05 \\
0.21 \\
0.55 \\
0.35 \\
0.12\end{array}$ & $\begin{array}{l}-4.2 \\
-3.0 \\
-3.8 \\
-3.8 \\
-3.5\end{array}$ & $\begin{array}{r}11 \\
19 \\
23 \\
123 \\
24\end{array}$ & $\begin{array}{r}8 \\
11 \\
14 \\
48 \\
7\end{array}$ & $\begin{array}{r}118 \\
142 \\
146 \\
195 \\
6\end{array}$ & $m S_{p}$ \\
\hline 4 & $\begin{array}{l}4 \\
3 \\
2 \\
1\end{array}$ & $\begin{array}{r}770 \\
610 \\
360 \\
40\end{array}$ & $\begin{array}{l}0.13 \\
0.45 \\
0.13 \\
0.06\end{array}$ & $\begin{array}{l}-6.8 \\
-5.8 \\
-4.2 \\
-2.0\end{array}$ & $\begin{array}{r}19 \\
17 \\
13 \\
9\end{array}$ & $\begin{array}{r}15 \\
13 \\
10 \\
8\end{array}$ & $\begin{array}{r}45 \\
247 \\
109 \\
20\end{array}$ & $m P_{s}$ \\
\hline 5 & $\begin{array}{l}3 \\
2 \\
1\end{array}$ & $\begin{array}{r}265 \\
120 \\
0\end{array}$ & $\begin{array}{l}0.51 \\
0.25 \\
0.09\end{array}$ & $\begin{array}{r}-0.8 \\
0.0 \\
+1.0\end{array}$ & $\begin{array}{l}17 \\
15 \\
11\end{array}$ & $\begin{array}{r}12 \\
9 \\
6\end{array}$ & $\begin{array}{r}352 \\
330 \\
83\end{array}$ & $m P$ \\
\hline
\end{tabular}

Table 3. Additional Cloud Description Data for Figs. 2 to 5

\begin{tabular}{|c|c|c|c|c|c|c|c|c|}
\hline \multirow{2}{*}{$\begin{array}{l}\text { Fig. } \\
\text { No. }\end{array}$} & \multicolumn{4}{|l|}{ Measured cloud } & \multicolumn{3}{|c|}{ Cloud above measured cloud } & \multirow{2}{*}{$\begin{array}{l}\text { Precipitation } \\
\text { on ground }\end{array}$} \\
\hline & $\begin{array}{l}\text { Cloud cover } \\
\text { (from ground) }\end{array}$ & Genus & $\begin{array}{l}\text { Height of } \\
\text { base }[\mathrm{m}]\end{array}$ & $\begin{array}{l}\text { Height of } \\
\text { top }[\mathrm{m}]\end{array}$ & $\begin{array}{l}\text { Cloud } \\
\text { cover }\end{array}$ & Genus & $\begin{array}{l}\text { Height } \\
{[\mathrm{m}]}\end{array}$ & \\
\hline 2 & $8 / 8$ & $\mathrm{Sc}, \mathrm{St}$ & 500 & 1600 & $<8 / 8$ & Ac & $\begin{array}{l}2000 \text { (above } \\
\text { this not any) }\end{array}$ & $\begin{array}{l}\text { Snow (light to } \\
\text { moderate) }\end{array}$ \\
\hline 3 & $8 / 8$ & $\mathrm{Sc}, \mathrm{St}$ & 800 & 2000 & $<8 / 8$ & $\mathrm{Ac}$ & $\begin{array}{l}2500 \text { (above } \\
\text { this not any) }\end{array}$ & $\begin{array}{l}\text { Not any (but about } 3 \mathrm{~h} \\
\text { after light snow) }\end{array}$ \\
\hline 4 & $5 / 8$ to $6 / 8$ & $\begin{array}{l}\mathrm{Cu}, \mathrm{Ac} \\
\text { to } \mathrm{As}\end{array}$ & 1600 & 2500 & Not any & & & Not any \\
\hline 5 & $8 / 8$ & $\mathrm{St}$ & 700 & 1200 & $4 / 8$ to $6 / 8$ & $\mathrm{Ac}$ & $\begin{array}{l}3800 \text { (above } \\
\text { this not any) }\end{array}$ & Not any \\
\hline
\end{tabular}

\section{Conclusions}

A. Concerning cloudphysical parameter liquid water content $L W C$ in dependence on height above cloud base, species of cloud, and precipitation on ground:

1. In stratus/cumulus cloudiness the maximum for $L W C$ wars reached in the lower third, the middle or in the upper third of the cloud. During little precipitation on ground the $L W C$ maximum was about in the middle and 3 hours after precipitation the maximum occurred in the lower third. Without precipitation the maximum was located in the upper third.

2. In stratus cloudiness without precipitation on ground the $L W C$ was growing with increasing height above cloud base and had its maximum direct beneath the cloud top.

3. The largest value for $L W C$ in the four ex- 
amples occurred at about $0.75 \mathrm{~g} / \mathrm{m}^{3}$. This value was obtained in a stratus/cumulus cloudiness with little precipitation on ground.

4. Calculations of the $L W C$ with the formula from Best (1952), see also Air Weather Service (1980), for convective clouds without entrainment resulted in the following: The measured maximum values for $L W C$ in the 4 figures were rather conform with the calculated values. This was valid as well for the maximum values in the stratus/cumulus cloudiness as for the maximum value in the stratus cloudiness. Rather conform here means that the difference between measured and calculated maximum values was between 38 and $10 \%$. Concerning the other $L W C$ values, the calculated values were a great deal larger than the measured ones.

The formula from Best (1952) which was used for calculating the $L W C$, runs as follows:

$$
L W C=\frac{216.7}{T}\left(\frac{P}{P_{0}} p_{0}-p\right)
$$

There are: $L W C\left[\mathrm{~g} / \mathrm{m}^{3}\right]=$ liquid water content; $T\left[{ }^{0} \mathrm{~K}\right]=$ temperature in a given cloud height; $P$ $[\mathrm{mbar}]=$ atmospheric pressure in a given cloud height; $P_{0}[\mathrm{mbar}]=$ atmospheric pressure in the cloud base; $p[\mathrm{mbar}]=$ saturation vapour density in a given cloud height; $p_{0}[\mathrm{mbar}]=$ saturation vapour density in the cloud base.

B. Concerning cloudphyiscal parameter particle size distribution represented by the median volume diameter $M V D$ in dependence on height above cloud base, species of cloud, and precipitation on ground:

1. In stratus/cumulus cloudiness with little precipitation on ground respectively 3 hours after precipitation the $M V D$ had marked maxima with 183 and $123 \mu \mathrm{m}$. In the first case it was located directly in the base of the cloud and in the second case in its lower third. In stratus/cumulus cloudiness the $M V D$ was growing without any relation to precipitation on an average with increasing height above cloud base.

2. In stratus cloudiness without precipitation on ground the $M V D$ was only changing little with increasing height above cloud base.

3. In stratus/cumulus cloudiness the $M V D$ had values between 7 and $19 \mu \mathrm{m}$ without any relation to precipitation.

4. In stratus cloudiness without precipitation on ground the $M V D$ had values between 11 and $17 \mu \mathrm{m}$.

5. Almost always the particle size distribution - i.e. here the $L W C$ in dependence on particle diameter $\mathrm{D}$ (see the right-hand parts of the figures) - had 2 maxima: One for small particles and another for big particles.

6. For all examples the particle concentration-represented by particle number per $\mathrm{cm}^{3}$ - was below 500 , between 4 and 416 . All clouds investigated were in maritime airmass.

C. Practical aspects of icing of aircraft

Temperature, liquid water content and particle size distribution are the most important cloudphysical parameters causing icing of aircraft. From the Figs. 1 to 5 with Table 1 the following results are derived:

1. In a stratus/cumulus cloudiness with precipitation on ground, or in one about three hours after that, there were difinite heigh regions in the lower third or in the middle of the cloud in which the $L W C$ was larger than $0.50 \mathrm{~g} / \mathrm{m}^{3}$. That implies a normalized icing-degree of moderate. In the other height regions the normalized icing-degree was only trace or light.

2 . In a stratus/cumulus cloudiness without precipitation on ground the largest $L W C$ was in the upper third and its value was here $0.45 \mathrm{~g} / \mathrm{m}^{3}$. That corresponds to a normalized icing-degree smaller than moderate.

3. In a stratus cloudiness without precipitation on ground the maximal $L W C$ was in the upper third, too. Its value was here about $0.50 \mathrm{~g} / \mathrm{m}^{3}$. At lower temperatures - at the example of Fig. 5 it was about $0{ }^{\circ} \mathrm{C}$ - the normalized icing-degree being moderate is to be expected.

4. The main reason for the aircraft-referred icing-degrees moderate to severe are great $M V D \mathrm{~s}$, and that means big particles, at relative high temperatures. From this follows, in the stratus/cumulus cloudiness with precipitation on ground respectively in one after three hours after that, there were small height regions in the lower third in which the aircraft-referred icing-degree moderate to severe must be expected.

5. In a stratus/cumulus cloudiness and in a stratus cloudiness without precipitation on ground there were no height regions with great $M V D$ s. Consequently, nowhere the aircraft-referred icingdegree moderate to severe must be expected. 


\section{Concluding Remarks}

The coarse analysis of further flight sections of the icing flights of the last years resulted in a confirmation of the mean values of the cloudphysical parameters given in Table 1 for the aircraft referred icing-degrees "trace" to "light" and "moderate" to "severe". A more precise analyis of the cloudphysical measurements in connection with the analysis of photographs of the iced underand upperside of the wing should result in more precise correlations of definite values of the cloudphysical parameters, and their time of acting, to the type of ice and by this to the aircraft-referred icing-degree. Under the type of ice, we understand the extent and the thickness of the ice accretion and its roughness. We hope to publish these results next year. At this occasion, the possibility shall be provided on the type of accreted ice, to assign definite values of the cloudphysical parameters and their influence on the aerodynamical factors drag coefficient, maximum lift coefficient and stall angle.

\section{References}

Air Weather Service 1980: Forcaster's Guide on Aircraft Icing. AWS/TR-80/001.

Best, A. C., 1952: Occurence of High Rats of Ice Accretion on Aircraft. Meteorological Office, Professional Notes No. 106.

Hoffmann, H.-E., Demmel, J., 1984: First Stage of Equipping a Type Do 28 as a Research Aircraft for Icing and First Research Results. ESA-TT-855.

Hoffmann, H.-E., 1986: Determination of Atmospheric Parameters by an Airborne Backscatter Probe. ESA-TT-982.

Hoffmann, H.-E., Demmel, J., 1986: DFVLR's Icing Research Aircraft Do 28, D-IFMP, and its Measuring Equipment. ESA-TT-972.

Hoffmann, H.-E., Roth, R., Demmel, J., 1986: Results of Icing Flights in Winter 1983/84: Dependence of Ice Accretion Thickness on Cloud Physics Parameters as well as Object and Cloud Parameters. ESA-TT-969.

Hoffmann, H.-E., Demmel J., Horst, H., Löbel, H., 1988: A Documentation of Cloudphysical Parameters of Vertical Profiles in Clouds (on Icing Flights in the Winter Months 1984 to 1988 ). (In preparation.)

Hoffmann, H.-E., 1988: Icing Degree Moderate to Severe: If and where in Clouds. Proceedings 16th Congress of the International Council of the Aeronautical Sciences, Vol. 2, 1801-1812.

Roach, W. T., Forrester, D. A., Crewe, M. E., Watt, K. F., 1984: An Icing Climatology for Helicopters. Meteorological Office, Special Investigations Memorandum 112.

Sand, W. R., Cooper, W. A., Politovich, M. K., Veal, D. L., 1984: Icing Conditions Encountered by a Research Aircraft. J. Climate Appl. Meteor., 23, 1427-1440.

Authors' address: H.-E. Hoffmann, R. Roth, DLR-Institut für Physik der Atmosphäre, D-8031 Wessling/Obb., Federal Republic of Germany. 